
Alamsyah, dkk

\title{
Pola Pengajian Kultural Ma'iyah Jamparing Asih di Bandung 2015-2018
}

\author{
Akbar Nur Alamsyah, Moeflich Hasbullah \\ Fakultas Adab dan Humaniora \\ Universitas Islam Negeri Sunan Gunung Djati Bandung \\ Email: akbarnuras@outlook.co.id
}

\begin{abstract}
The Islamization in Indonesia since the 7th century has also involved the transformation of Islamic religious knowledge, also called pengajian (Islamic learning). The study in its development is divided into two types; First, non-formal Quranic recitation such as Quranic recitation at home, langgar and mosque. Secondly, formal Islamic learning is institutionalized like in a pesantren. Islamic boarding schools continue the tradition of formal learning while non-formal recitation has developed since the beginning of Islamization in the 7th century and has still lived in various forms. Non-formal learning because of its egalitarian and flexible nature so that there are no specific ties which are more attractive to many people to attend the recitation. This study aims to determine how the history, methods and study patterns used by Maiyah Jamparing Asih. The method used in this study is the historical research method in four stages such as heuristics, criticism, interpretation and historiography. The results of this study show that the Islamic learning of Maiyah Jamparing Asih was established in November 2015 by four people namely Wawan, Mufti, Andityas and Nissa which were approved by Cak Nun and Sheikh Kamba at his home in Jakarta. The learning pattern or method used by Maiyah Jamparing Asih in 2015 and 2016 almost entirely uses the general learning pattern, then in 2017 used the way of interpreting pattern of the Quran and in 2018 used the general learning pattern, and the recitation method used in 2015 and 2016 uses the lecture method, then in 2017 and 2018 it used the mudzakarah method.
\end{abstract}

Keywords: Islamic learning, quranic recitation, Maiyah. 
Pola Pengajian Kultural Ma'iyah Jamparing Asih di Bandung 2015-2018| Akbar Nur Alamsyah, dkk

\section{Pendahuluan}

Masuknya Islam ke Indonesia sejak awal abad ke-7 $\mathrm{M}^{1}$ menyertakan transformasi keilmuan agama Islam. Hal itu terlaksana karena adanya interaksi antara pedagang (mubaligh) dan masyarakat sekitar. ${ }^{2}$ Komunikasi yang terjalin pada saat itu antara mubaligh dan masyarakat lebih banyak memberikan pembelajaran akhlak dalam tata cara berprilaku sehingga pembelajaran ini lebih menekankan pada contoh keteladanan dalam sikap hidup sehari-hari. Dengan demikian pendidikan agama Islam telah berkembang bersamaan dengan Islamisasi itu sendiri.

Proses pendidikan atau pengajian hingga hari ini masih dijalankan. Namun dalam rentang waktu yang panjang, istilah pengajian memiliki dua fakta berbeda. Pertama, ia dimaknai sebagai pembelajaran agama Islam. Dari istilah pengajian meliputi semua hal yang berkaitan dengan ilmu-ilmu keislaman. Sementara yang kedua, pembacaan ayat suci alquran dimaknai sebagai dasar terpenting dalam pembelajaran agama Islam. Menetapkan alquran sebagai dasar pembelajaran agama Islam bukan hanya karena perspektif kebenaran dan keimanan semata, melainkan juga kebenaran keduanya telah dapat dibuktikan oleh akal berdasarkan sejarah dan pengalaman manusia. ${ }^{3}$

Dengan perubahan sosial, budaya dan politik di Indonesia, kedua jenis pembelajaran agama Islam terbagi menjadi dua macam: Pertama, pembelajaran secara nonformal seperti pengajian di rumah, langgar dan masjid. Kedua, pembelajaran secara formal seperti di pesantren.

Seperti halnya pesantren yang melanjutkan tradisi pengajian formal keagamaan, tradisi pengajian nonformal keagamaan yang dikembangkan sejak awal abad ke-7 M masih tetap hidup dalam berbagai bentuk. Pengajian nonformal yang sifatnya tidak resmi seperti pesantren yang kemudian hidup di masjid-masjid dan di rumah-rumah dan lain sebagainya, bentuk seperti ini karena sifatnya nonformal maka jauh lebih fleksibel sehingga kemudian tidak ada ikatan-ikatan tertentu. ${ }^{4}$

1 A. Hasjmy, , Sejarah Masuk dan Berkembangnya Islam di Indonesia, (A1Ma'arif, 1993), 177.

2 Noeng Muhadjir, Ilmu Pendidikan dan Perubahan Sosial Suatu Teori Pendidikan, (Yogyakarta: Rake Sarasin 1987), 15.

3 Aisyah Nursyarief, "Pendidikan Islam di Indonesia Dalam Lintasan Sejarah", Jurnal Lentera Pendidikan, Vol. 17 No. 2, 2014. 256.

${ }^{4}$ Martin van Bruinessen, Kitab Kuning, Pesantren dan Tarekat, (Yogyakarta: Gading Publishing 2015), 105. 
Pola Pengajian Kultural Ma'iyah Jamparing Asih di Bandung 2015-2018| Akbar Nur Alamsyah, dkk

Sementara perkembangan sejarah pengajian nonformal juga terus berkembang dalam berbagai bentuk dan banyak sifatnya. Salah satu contohnya yaitu bersifat egaliter di mana setiap orang bebas untuk datang ke pengajian tersebut. Biasanya, pengajian dengan sifat ini biasanya terbuka untuk umum, tidak memandang suku, ras, profesi, latar belakang pendidikan, strata ekonomi dan hirarki sosial masyarakat lainnya. ${ }^{5}$

Masuk ke akhir abad $20 \mathrm{M}$ atau pada masa Orde Baru memunculkan salah satu satu fenomena baru pengajian nonformal yang kemudian disebut sebagai pengajian Maiyah. Pengajian tersebut dikembangkan oleh Muhammad Ainun Nadjib atau yang lebih dikenal dengan nama Cak Nun.

Berawal dari sebuah pengajian rutin keluarga di Jombang Jawa Timur pada bulan Oktober 1993, pengajian ini dinamai Padhangmbulan. Sebagai sebuah pengajian nonformal yang dikembangkan oleh Cak Nun, pengajian ini diselenggarakan pada tanggal 15 kalender Jawa (lebih tepatnya pada setiap malam bulan purnama) setiap bulannya. Sosok Cak Nun yang pada saat itu di kenal masyarakat Indonesia berkat tulisan-tulisan bernas di kolom-kolom surat kabar nasional dan menjadi narasumber di berbagai forum diskusi merupakan daya tarik bagi masyarakat untuk menghadiri pengajian Padhangmbulan. ${ }^{6}$

Sejak awal didirikan pada tahun 1993 hingga hari ini, pengajian yang dikembangkan oleh Cak Nun ternyata memunculkan pengajian-pengajian serupa di berbagai daerah. Seiring dengan perkembangan itu pada tahun 2015 di wilayah Jawa Barat khususnya di Bandung, sejumlah orang yang sering mengikuti pengajian Cak Nun berkumpul bersama-sama mendirikan pengajian Jamparing Asih.

Untuk mempermudah kajian, penelitian ini dibatasi oleh dua hal: yaitu batasan waktu dan tempat. Pertama, batasan waktu diperlukan untuk mempermudah pengkajian suatu peristiwa pada penelitian ini dalam kurun waktu tahun 2015-2018, interval tersebut dipilih berdasarkan ketersediaan sumber-sumber data dan keterbatasan kemampuan peneliti dalam melakukan penelitian. Kedua, batasan tempat diperlukan untuk memudahkan pencarian sumber-sumber data yang relevan dengan penelitian maka tempat yang

\footnotetext{
${ }^{5}$ Fahmi Agustian, Pengajian Kok Begitu: 10 Hal untuk Millenial Ketahui Tentang Sinau Bareng Cak Nun dan Kiai Kanjeng. (Progress: Yogyakarta 2019), 1

6 Komunitas Maiyah Kenduri Cinta, Padhangmbulan Sebagai Ibu Maiyah. (Jakarta: Redaksi Kenduri Cinta 2016), 1.
} 
Pola Pengajian Kultural Ma'iyah Jamparing Asih di Bandung 2015-2018| Akbar Nur Alamsyah, dkk

menjadi sumber penggalian informasi mengenai penelitan ini adalah komunitas pengajian Maiyah Jamparing Asih.

Berdasarkan pertimbangan, ada beberapa alasan mengapa kajian ini layak diangkat. Pertama, alasan subjektif. Secara subjektif karena ketertarikan terhadap kajian ini. Kedua, karena pengajian yang dikembangkan oleh Cak Nun (yang kemudian disebut pengajian Maiyah) terbilang sangat pesat pertumbuhannya di berbagai daerah. Maka dari itu penelitian ini menarik untuk dibahas secara mendalam khususnya yang ada di Bandung, bagaimana sejarah berdirinya pengajian Maiyah. Bagaimana sejarah berdirinya pengajian Maiyah Jamparing Asih. Pola dan metode apa yang digunakan pengajian Maiyah Jamparing Asih tahun 2015-2018.

\section{Metode Penelitian}

Dalam setiap penelitian hal yang pertama harus dilakukan oleh peneliti untuk memulai pembahasan adalah memperoleh informasi yang diperlukan berupa data-data yang tersedia dalam sumber-sumber serta bahanbahan yang erat kaitannya dengan penelitian yang sedang dilakukuan.

Adapun sumber dalam sejarah dibagi menjadi dua kategori yaitu: sumber primer dan sumber sekunder. Sumber primer adalah sumber dari kesaksian orang yang langsung terkait dengan peristiwa atau bagian dari peristiwa atau dokumen yang membahas peristiwa. Sedangkan sumber sekunder adalah sumber yang berupa ungkapan tentang peristiwa yang dilakukan oleh orang kedua atau bukan pelaku dan saksi mata langsung pada saat peristiwa berlangsung.

Terkait penelitian yang sedang dilakukan mengenai " Pola Pengajian Kultural Maiyah Jamparing Asih di Bandung Tahun 2015-2018”, maka bahan yang dikumpulkan berupa buku, artikel, foto dan video. Penelusuran sumber tersebut dilakukan di pengajian Maiyah Jamparing Asih, perpustakaan Univeristas Islam Negeri Sunan Gunung Djati di Bandung, perpustakaan Emha Ainun Nadjib di Yogyakarta serta melakukan wawancara dengan guru atau marja' dan jamaah Maiyah, melihat dan menyimak beberapa video pengajian Maiyah yang didokumentasikan lalu melakukan proses penyederhanaan dengan memilih beberapa sumber yang ada yang sesuai dengan representasi objek penelitian yang sedang dilakukan. Adapun data yang menjadi sumber primer yaitu:

1. Anonim "Sunda Mengasuh" Redaksi Jamparing Asih (2015) 
Pola Pengajian Kultural Ma'iyah Jamparing Asih di Bandung 2015-2018| Akbar Nur Alamsyah, dkk

2. Anonim "Kongsi Ka Cai" Redaksi Jamparing Asih (2016)

3. Anonim "Pengabdian Tanpa Pengakuan" Redaksi Jamparing Asih (2016)

4. Anonim "Manusia Tadah Hujan" Redaksi Jamparing Asih (2016)

5. Anonim "Sakaba-kaba In(s)tan" Redaksi Jamparing Asih (2016)

6. Anonim "Isyarah Kaasih" Redaksi Jamparing Asih (2016)

7. Anonim "Mengasah Puasa" Redaksi Jamparing Asih (2016)

8. Anonim "Pareumeun Obor" Redaksi Jamparing Asih (2016)

9. Anonim "Korek Si Kuping" Redaksi Jamparing Asih (2016)

10. Anonim "1001 Maklum” Redaksi Jamparing Asih (2016)

11. Anonim "Lemah Cai Kuring, Lemah Cai Nu Sajati" Redaksi Jamparing Asih (2016)

12. Anonim "Born Identity" Redaksi Jamparing Asih (2017)

13. Anonim "Suci Sang Primadogma" Redaksi Jamparing Asih (2017)

14. Anonim "Manusia Goa" Redaksi Jamparing Asih (2017)

15. Anonim "Shut Down" Redaksi Jamparing Asih (2017)

16. Anonim "Wilayah Aba-aba Abu-abu" Redaksi Jamparing Asih (2017)

17. Anonim “ Wasitaning Budhi Sonya Kanthi” Redaksi Jamparing Asih (2017)

18. Anonim "Tetring Ka Kanjeng Nabi" Redaksi Jamparing Asih (2017)

19. Anonim "Gagap Gempita Spiritual" Redaksi Jamparing Asih (2018)

20. Anonim "Samagaha Pikir" Redaksi Jamparing Asih (2018)

21. Anonim "Dogdog Pangrewong” Redaksi Jamparing Asih (2018)

22. Anonim "Sidik Paningal" Redaksi Jamparing Asih (2018)

23. Anonim "Manusia Puasa" Redaksi Jamparing Asih (2018)

24. Anonim "Mudik (Bandung Indonesia Pulang Pergi)" Redaksi Jamparing Asih (2018)

25. Anonim "Colak-Colek Calik" Redaksi Jamparing Asih (2018)

26. Anonim "Ternak Ilmu(wan)” Redaksi Jamparing Asih (2018)

27. Anonim "Ge Er (Tak sudah-sudah)" Redaksi Jamparing Asih (2018)

28. Anonim "Bakiak" Redaksi Jamparing Asih (2018)

29. Anonim “Tumpeng Madangan” Redaksi Jamparing Asih (2018) 
Pola Pengajian Kultural Ma'iyah Jamparing Asih di Bandung 2015-2018| Akbar Nur Alamsyah, dkk

30. Anonim "Sosoroh Kojor" Redaksi Jamparing Asih (2018)

31. Emha Ainun Nadjib "Orang Maiyah” Bentang Pustaka (2015)

32. Emha Ainun Nadjib "Allah Tidak Cerewet Seperti Kita” Naura (2019)

33. Emha Ainun Nadjib "Mati Ketawa Ala Refotnasi” Bentang Pustaka (2016)

34. Emha Ainun Nadjib "Saat-saat Terakhir Bersama Soeharto" Bentang Pustaka (2016)

35. Emha Ainun Nadjib "Hidup Itu Harus Pintar Ngegas dan Ngerem" Naura (2018)

36. Muhammad Nursamad Kamba "Kids Zaman Now Menemukan Kembali Islam" Ilman (2018)

Kemudian terdapat sumber-sumber yang membantu dalam penulisan penelitian ini yaitu sumber sekunder berupa buku Jalan Sunyi Emha karya Ian L. Betts, Spiritual Pemikiran dan Perenungan Emha Ainun Nadjib karya Prayogi R. Saputra, Semesta Emha Ainun Nadjib karya Sumasno Hadi, Kitab Kuning, Pesantren dan Tarekat karya Martin van Bruinessen, Budaya dan Masyarakat karya Kuntowijoyo, Tradisi Pesantren: Studi Pandangan Hidup Kyai dan Visinya Mengenai Masa Depan Indonesia karya Zamakhsyari Dhofier, skripsi Pop Culture Maiyah Gambang Syafa'at di Semarang karya Ahmad Ulul Albab, skripsi Sikap Jamaah Maiyah Yogyakarta Terhadap Teknik Penanyangan Program Mocopat Syafa'at di Adi TV karya Muhammad Muslim dan skripsi Kebermaknaan Hidup Jamaah Maiyah Yogyakarta karya Ahmad Rosyid.

Selain sumber tulisan maupun dokumentasi berupa foto dan audio, sumber penulisan dalam penelitian yang sedang dilakukan juga menggunakan metode wawancara atau sumber lisan. Sumber lisan ini berkaitan dengan bagaimana pandangan jamaah Maiyah terhadap pengajian Maiyah.

Tahapan selanjutnya dalam metode sejarah setelah pengambilan datadata dari sumber yang telah dikumpulkan melalui proses heuristik yaitu dengan melakukan kritik terhadap sumber yang diperoleh untuk menentukan otentitas dan kredibilitas. Proses kritik ini adalah langkah yang dilakukan untuk menguji sumber yang didapatkan dengan kualifikasi bentuk, bahan dan jenis dari naskah atau dokumen yang nantinya menentukan bagaimana validitas teks dan isi dari data-data yang kemudian menjadi fakta-fakta 
Pola Pengajian Kultural Ma'iyah Jamparing Asih di Bandung 2015-2018| Akbar Nur Alamsyah, dkk

dengan demikian tahapan kritik ini dibagi menjadi dua bagian yaitu kritik intern dan kritik ekstern.

Kritik intern adalah suatu cara untuk mendapatkan fakta-fakta yang berkaitan dengan fokus penelitian karena dalam setiap sumber tak lepas dari muatan fakta lain yang belum tentu sesuai, paling tidak pada peristiwaperistiwa tertentu sumber memberikan informasi yang bisa jadi adalah reproduksi dari teks karena secara bentuk berbeda dengan yang sesungguhnya hingga akhirnya tentu dapat menimbulkan distorsi. ${ }^{7}$

Kritik ekstern pada umumnya digunakan untuk meneliti otentitas sumber secara bentuk dan menguji material kertas atau bahan juga tanggal dan tanda yang terdapat di dalam teks. ${ }^{8}$ Upaya ini diharapkan dapat memberikan kecocokan antara bahan naskah atau dokumen dengan teks pada zamannya. $^{9}$

Setelah melewati dua proses yaitu heuristik dan kritik, maka dari proses kritik yang telah dilakukan akan ditemukan fakta-fakta kemudian mencoba untuk menganalisis dan ditelaah lebih mendalam untuk mencari keterkaitan antarfakta sehingga tersusun sebuah rekonstruksi yang baik melalui fakta tersebut, peristiwa ini diolah dengan teori. Proses ini kemudian disebut sebagai interpretasi atau penafsiran sejarah. ${ }^{10}$

Sebagai penelitian sejarah, penelitian ini akan menjelaskan dua hal; pertama, pengajian Maiyah Jamparing Asih bisa disebut sebagai pendidikan humaniora sebagaimana yang dijelaskan oleh Kuntowijoyo. ${ }^{11}$ Sementara yang kedua, dari sisi sejarah, pengajian Maiyah ini akan dibahas secara kronologis historis.

Menurut Kuntowijoyo, pendidikan humaniora adalah proses perubahan sikap atau tata laku seseorang dalam usaha mendewasakan manusia melaui pengajaran dan pelatihan. ${ }^{12}$ Menurutnya lagi, pendidikan humaniora terbagi menjadi dua bagian yakni baik secara formal melalui

\footnotetext{
${ }^{7}$ Louis Gottscalk, Mengerti Sejarah. (Jakarta: UI Press 1986), 35-38.

${ }^{8}$ Paul Veyne, Writing History: Esay on Epistimology. (Conneticut: Wesleyan University Press 1984), 7-13.

${ }^{9}$ Louis Gottscalk, Mengerti Sejarah. (Jakarta: UI Press 1986), 35-38.

${ }^{10}$ Kuntowijoyo, Pengantar Ilmu Sejarah, (Yogyakarta: Bentang Budaya 2001), 103-104.

${ }^{11}$ Kuntowijoyo, Budaya dan Masyarakat. (Yogyakarta: Tiara Wacana 2006), 4749. 49.

${ }^{12}$ Kuntowijoyo, Budaya dan Masyarakat. (Yogyakarta: Tiara Wacana 2006), $47-$
} 
Pola Pengajian Kultural Ma'iyah Jamparing Asih di Bandung 2015-2018| Akbar Nur Alamsyah, dkk

sebuah lembaga pendidikan, maupun secara nonformal melalui bentuk komunikasi sosial. $^{13}$

Dilihat dari teori ini Maiyah bisa dikatakan sebagai pendidikan humaniora yang disebut oleh Kuntowijoyo karena ia mengedepankan nilainilai humanis. ${ }^{14}$ Nilai-nilai humanis yang terdapat dalam pengajian itu memberikan pengajaran dan pelatihan bagaimana seseorang menjadi manusia yang utuh berdaulat atas dirinya sendiri dan berbuat baik bagi sesama manusia maupun sesama makhluk ciptaan-Nya. Selain itu, pengajian ini nampaknya lebih condong kepada bentuk nonformal karena tidak menjadi suatu lembaga pengajian konvensional pada umumnya.

Untuk meletakannya dalam kajian sejarah, Maiyah akan dijelaskan dalam susunan peristiwa-peristiwa. Ini berarti setiap pengajian itu akan disusun berdasarkan peristiwa mana yang lebih dahulu dan diikuti oleh peristiwa lain; sehingga terbentuk susunan atau struktur peristiwa sejarah sesuai dengan batasan temporal. Dengan cara itu kita bisa melihat perkembangan dan perubahan sebagai karakter inti kajian sejarah.

Adapun tahapan akhir dalam penelitian ini adalah tahapan historiografi yaitu tahapan penulisan atau pelaporan atas penelitian yang dilaksanakan oleh penulis. Mengingat penulisan dalam sejarah mengedepankan aspek kronologis dari pembahasan yang sedang dilakukan makan seluruh rangkaian dari laporan ini mempunyai sistematika sebagai berikut: Susunan penulisan ini terdiri dari $4 \mathrm{Bab}$, Bab 1 membahas tentang latar belakang hingga proses penulisan akhir, Bab 2 difokuskan kepada pembahasan situasi yang melingkupi sektiar peristiwa, Bab 3 mengurai tentang pokok permasalahan yang sedang diteliti dan pada Bab 4 yang merupakan Bab terakhir berisikan simpulan dan saran dari penulis atas materi pokok studi penulis.

\section{Hasil dan Pembahasan}

\section{Sejarah Berdirinya Pengajian Maiyah}

Sejarah berdirinya pengajian Maiyah secara nasional melewati dua tahapan. Yang pertama sebelum disebut Maiyah yaitu berupa forum-forum pengajian seperti Padhangmbulan di Jombang, Mocopat Syafaat di

${ }^{13}$ Kuntowijoyo, Budaya dan Masyarakat. (Yogyakarta: Tiara Wacana 2006), 4749.

${ }^{14}$ Kuntowijoyo, Budaya dan Masyarakat. (Yogyakarta: Tiara Wacana 2006), $47-$ 49. 
Pola Pengajian Kultural Ma'iyah Jamparing Asih di Bandung 2015-2018| Akbar Nur Alamsyah, dkk

Yogyakarta dan Gambang Syafaat di Semarang. Kemudian yang kedua setelah disebut Maiyah, sejak Kenduri Cinta di Jakarta dan Bangbang Wetan di Surabaya.

\section{Padhangmbulan di Jombang}

Tahapan berdirinya Maiyah adalah pengajian Padhangmbulan di Jombang. Pengajian ini dimulai pada bulan Oktober 1993 sampai hari ini. Pengajian ini menjadi titik awal munculnya pengajian Maiyah, karena dari pengajian ini lah kemudian tersebar jenis-jenis pengajian serupa dengan nama-nama yang berbeda akan tetapi format acara dan hakikatnya sama.

Secara garis besar dari tahun 1993 sampai dengan tahun 2015 pengajian Padhangmbulan mengalami perubahan terutama pada tahap-tahap awal, karena sejak tahun 1998 hingga 2015 semua hampir tidak terjadi perubahan yang signifikan hanya pada jumlah orang, lokasi pengajian dan tata letak panggung.

Ketika itu pada tahun 1992 berlangsung pertemuan keluarga besar Muhammad Ainun Nadjib (yang selanjutnya disebut Cak Nun) di Yogyakarta. Ada pun hasil dari pertemuan tersebut memutuskan untuk menggelar pengajian dengan rutin sebulan sekali yang oleh Cak Nun diberi nama pengajian Padhangmbulan. Maka dari itu beberapa orang menggagas pengajian tersebut termasuk Cak Nun di dalamnya yang menyepakati beberapa hal seperti tanggal dan lokasi dilaksanakannya pengajian. ${ }^{15}$

Ketika pertama kali pengajian Padhangmbulan dilaksanakan di Jombang pada tanggal 15 kalender Jawa (lebih tepatnya pada setiap malam bulan purnama) Oktober 1993 seperti yang telah disepakati sebagian besar keluarga hadir di depan Musola Desa Menturo, Sumobito, Jombang, Jawa Timur. Orang yang hadir mengikuti pengajian tersebut pada waktu itu berjumlah 40 termasuk keluarga besar Cak Nun sendiri; dan nama-nama yang tercatat: M. Adenan, Zainuri, Abdul Kholiq, Kasdu, Faridah, Sarofah, Marhamah, Nuchin, Muslikh, Bambang Ma'ruf, Margin, Sumadi, Mukhlis, Nasrib, Kanip, Saiful Alam, Mari, dan Sulkhan Mulud. Nama-nama tersebut merupakan sahabat-sahabat Cak Nun. ${ }^{16}$

15 Dokumentasi Youtube Caknun.com, Membangun Negeri Maiyah. https://youtu.be/kE6qajVBgHc diakses pada 13 Februari 2020 pukul 20.25 WIB.

16 Rony K. Pratama, Rubrik Maiyahan. Mencari Akar Meneladani Sesepuh Padhangmbulan. https://www.caknun.com/2019/mencari-akar-meneladani-sesepuhpadhangmbulan/ diakses pada 31 Januari 2020 pukul 11.21 WIB. 
Pola Pengajian Kultural Ma'iyah Jamparing Asih di Bandung 2015-2018| Akbar Nur Alamsyah, dkk

\section{Mocopat Syafaat di Yogyakarta}

Berbeda dengan proses terbentuknya Padhangmbulan, proses terbentuknya Mocopat Syafaat tidak melalui rembuk keluarga besar Cak Nun, karena ini merupakan inisiatif ia sendiri guna merespon kondisi sosial, budaya dan politik pada tahun 1999. Kemudian pengajian ini rutin dilaksanakan setiap tanggal 17 Masehi di kediaman Cak Nun atau lebih tepatnya terletak di Taman Tirto, Kasihan, Bantul Yogyakarta. ${ }^{17}$

Secara garis besar dari tahun 1999 hingga tahun 2015 pengajian Mocopat Syafaat mengalami perubahan terutama pada tahap-tahap awal, karena sejak tahun 2001 hingga 2015 semua hampir tidak terjadi perubahan yang signifikan hanya pada jumlah orang, lokasi pengajian dan tata letak panggung.

Pengajian ini pertama kali diselenggarakan pada tanggal 17 Juni 1999 di kediaman Cak Nun di Yogyakarta. Pada tahap awal pengajian ini berlangsung tampaknya ada pemisahan tempat duduk untuk jamaah laki-laki dan perempuan yang hampir semuanya mengenakan pakaian putih-putih. ${ }^{18}$ Acara ini lebih digunakan oleh Cak Nun untuk menjawab pertanyaanpertanyaan yang muncul dari jamaah atau merundingkan apa saja dengan keadilan berpikir dan kejernihan hati. Sehingga ia tidak berceramah seperti di acara-acara yang lain. ${ }^{19}$

Mocopat Syafaat dalam perkembangannya terus berjalan hingga saat ini dengan berbagai perubahan dan perkembangan dalam format acara maupun hal lainnya. Diperkirakan sekitar tahun 2007 jamaah laki-laki dan perempuan tidak lagi dipisah tempat duduknya, lalu lokasi acara pun berubah yang awalnya dilaksanakan di dalam rumah Cak Nun berpindah ke halaman depan rumah Cak Nun, mengingat bertambahnya jumlah orang yang hadir mengikuti pengajian baik dari masyarakat sekitar mau pun dari daerah lainnya. Maka atas dasar itu dibuatlah panggung dengan tinggi kurang lebih

17 Dokumentasi Youtube Caknun.com, Membangun Negeri Maiyah. https://youtu.be/kE6qajVBgHc diakses pada 16 Februari 2020 pukul 16.37 WIB.

18 Dokumentasi Youtube Caknun.com, Membangun Negeri Maiyah. https://youtu.be/kE6qajVBgHc diakses pada 16 Februari 2020 pukul 16.37 WIB.

19 Dokumentasi Youtube Caknun.com, Membangun Negeri Maiyah. https://youtu.be/kE6qajVBgHc diakses pada 16 Februari 2020 pukul 16.37 WIB. 
Pola Pengajian Kultural Ma'iyah Jamparing Asih di Bandung 2015-2018| Akbar Nur Alamsyah, dkk

$50 \mathrm{~cm}$ agar jamaah yang dari kejauhan bisa melihat narasumber yang ada di panggung. ${ }^{20}$

\section{Gambang Syafaat di Semarang}

Beberapa bulan setelah Mocopat Syafaat dibentuk atau lebih tepatnya pada 25 Desember 1999 muncul pengajian serupa di Semarang dengan nama Gambang Syafaat. Proses terbentuknya Gambang Syafaat ini dikarenakan Cak Nun dan Kiaikanjeng pernah mengisi sebuah acara pengajian di Semarang. Kemudian beberapa orang yang mengikuti pengajian tersebut, berembuk untuk membentuk sebuah komunitas pengajian di Semarang.

Secara garis besar dari tahun 1999 hingga tahun 2015 pengajian Gambang Syafaat mengalami perubahan terutama pada tahap-tahap awal, karena sejak tahun 2003 hingga 2015 semua hampir tidak terjadi perubahan yang signifikan hanya pada jumlah orang, lokasi pengajian dan tata letak panggung.

Tiga tahun Gambang Syafaat berlangsung atau sekitar tahun 2002, pengajian ini sempat mengalami fase penurunan pada jumlah jamaah dan hampir hilang. Hal ini disampaikan langsung oleh salah satu jamaah yang aktif menghadiri pengajian sejak awal diselenggarakan hingga hari ini. ${ }^{21}$

Namun di tahun 2003 hingga saat ini jumlah jamaah yang menghadiri pengajian mengalami kenaikan daripada tahun 2002. Ketika jumlah jamaah yang hadir ke pengajian bertambah banyak, maka ada pemindahan lokasi pengajian yang awalnya dilaksanakan di Aula dalam berpindah ke halaman depan Mesjid Baiturrahman, Semarang. Tentunya ini berkat komitmen antar jamaah pengajian untuk tetap melaksanakan pengajian rutin setiap tanggal $25 .^{22}$

Mulai dari pengajian Gambang Syafaat ada sedikit perubahan pada pengajian-pengajian serupa di berbagai daerah yaitu dengan adanya penentuan tema untuk sesi dialog dua arah. Mukadimah dibuat untuk

${ }^{20}$ Witarko dan Junanah, Ringkasan Tesis Pendidikan Nilai-Nilai Multikultural Dalam Forum Maiyah Mocopat Syafaat di Tamantirto Kasihan Bantul. (Yogyakarta:TP 2017). 13.

${ }^{21}$ Anif Khoiriyah, Skripsi Implementasi Metode Dakwah Untuk Mengembangkan Kecerdasan Spiritual Jamaah Pada Maiyah Gambang Syafaat. (Universitas Islam Negeri Walisongo: Semarang 2019), 42.

22 Anif Khoiriyah, (2019), Skripsi Implementasi Metode Dakwah Untuk Mengembangkan Kecerdasan Spiritual Jamaah Pada Maiyah Gambang Syafaat. Universitas Islam Negeri Walisongo: Semarang. 42. 
Pola Pengajian Kultural Ma'iyah Jamparing Asih di Bandung 2015-2018| Akbar Nur Alamsyah, dkk

menjelaskan secara singkat mengenai tema yang akan dibahas disetiap pengajian berlangsung.

Penentuan tema disetiap pengajian biasanya bersumber dari keadaan sosial yang sedang terjadi di masyarakat, atau bersumber dari tulisan-tulisan yang dimuat web caknun.com, buku-buku Cak Nun, atau dari sumbersumber lain yang biasanya didiskusikan terlebih dahulu oleh beberapa jamaah pengajian Gambang Syafaaat. Beberapa orang dari jamaah kerap mengadakan pertemuan sebelum pengajian dilaksanakan guna menentukan tema yang akan dibahas.

Jika dilihat pengajian yang dibentuk oleh Cak Nun dan keluarganya yakni Padhangmbulan yang menjadi cikal-bakal penyebaran pengajian serupa yang kemudian dinamai pengajian Maiyah pada tahun 2000-an.

Maiyah secara etimologi berasal dari bahasa Arab, yaitu ma'a, yang berarti "dengan, bersama, dan beserta". Lalu Ma'iya yang berarti "bersamaku". Sehingga ma'iyah berarti "kebersamaan”. Selanjutnya ma'iyah berubah sesuai dialek Jawa menjadi Maiyah. Maiyahan sendiri bisa dimaknai seseorang atau kelompok orang dalam kondisi mengikuti acara pengajian Maiyah. $^{23}$

Syeikh Kamba memaparkan bahwa yang jamaah Maiyah lakukan saat ini berkumpul dalam setiap maiyahan bukan karena ilmu pengetahuan akan tetapi karena Allah mengikat seluruh jamaah dengan cinta dan kelembutan. Konsep cinta dan rasa kekeluargaan yang sangat erat yang dibangun di Maiyah merupakan anugerah dari Allah. ${ }^{24}$

\section{Kenduri Cinta di Jakarta}

Enam bulan setelah dibentuknya pengajian Gambang Syafaat di Semarang, muncul pengajian serupa di Jakarta dengan nama Kenduri Cinta pada 17 Juni 2000. Pada mulanya pengajian ini dibentuk atas dasar keinginan jamaah pengajian Padhangmbulan yang berdomisili di Jakarta, tentunya hal itu disambut baik oleh Cak Nun. Komunitas pengajian ini rutin menyelenggarakan pengajian pada hari Jumat kedua setiap bulannya di Taman Ismail Marzuki, Jakarta. ${ }^{25}$

23 Ahmad Fuad Effendy, Ma'iyah di dalam Al-Qur'an Kajian Tafsir Tematik. (Jombang:TP 2009). 5.

${ }^{24}$ Muhammad Nursamad Kamba, Wawancara dengan salah satu marja' Maiyah pada 12 Maret 2020 pukul 15.51 WIB.

${ }^{25}$ Redaksi Kenduri Cinta, Padhangmbulan Sebagai Ibu Maiyah.Jakarta: TP 2016), 1. 
Pola Pengajian Kultural Ma'iyah Jamparing Asih di Bandung 2015-2018| Akbar Nur Alamsyah, dkk

Pada tahap-tahap awal pengajian ini terlaksana atau sekitar tahun 2000-an hampir seluruh format acaranya menduplikasi pengajian Padhangmbulan. Ada pun susunan acara pengajian ini yaitu; pertama, pembacaan hadoroh. Kedua, membaca selawat dan wirid bersama-sama. Ketiga, membaca beberapa ayat alquran dan yang terakhir barulah sesi dialog dua arah antara narasumber dan jamaah dimulai. Disesi dialog dua arah yang durasinya kurang lebih 4 jam kerap ada penampilan kesenian. ${ }^{26}$

Kenduri Cinta berlangsung selama bertahun-tahun hingga hari ini. Nampaknya ada hal-hal yang menarik dalam pengajian ini. Jika di setiap pengajian konvensional jamaah laki-laki dan perempuan dipisah tempat duduknya, berbeda dengan pengajian ini di mana jamaah laki-laki dan perempuan duduk berdampingan.

Mungkin ini adalah salah satu alasan mengapa pengajian seperti ini banyak diminati masyarakat karena bersifat egaliter. Tidak membedabedakan gender, status sosial, suku, ras dan agama. Semuanya berposisi sama yakni sebagai makhluk Allah SWT. Kemudian hal lainnya yang menarik yakni desain panggung yang hanya sekitar $50 \mathrm{~cm}$ dan hampir tidak ada jarak sama sekali dengan jamaah. Mungkin karena hal ini jamaah merasa semakin kerasan mengikuti pengajian dan merasa dekat dengan Cak Nun.

\section{Bangbang Wetan di Surabaya}

Berbeda dengan pengajian Kenduri Cinta, cikal-bakal munculnya Bangbang Wetan sudah mulai terlihat sejak tahun 2000-an. Pada saat itu ada dua pengajian yang diisi oleh Cak Nun, pengajian itu bernama Haflah Shalawat dan Tombo Ati. Haflah Shalawat diadakan pada hari minggu setiap akhir bulan di komplek Masjid Al-Akbar Surabaya, yang dimulai pagi hari dengan pembacaan selawat dan diisi oleh berbagai grup-grup selawat yang ada di Surabaya. Kemudian, puncak dari pengajian tersebut diisi dengan ceramah-ceramah dari Cak Nun. Pengajian ini lebih banyak diikuti oleh ibuibu dan grup-grup selawat. Sedangkan pengajian Tombo Ati dilaksanakan di Hotel Elmi yang rata-rata jamaahnya berada pada tatanan ekonomi menengah ke atas serta kaum intelektual.

${ }^{26}$ Rini Wulan, Skripsi Retorika Emha Ainun Nadjib dalam Kajian Kenduri Cinta di Taman Ismail Marzuki Jakarta Pusat. (Bandung: Universitas Islam Negeri Sunan Gunung Djati Bandung 2018), 47. 
Pola Pengajian Kultural Ma'iyah Jamparing Asih di Bandung 2015-2018| Akbar Nur Alamsyah, dkk

Maka dari itu, disiasati bahwa Bangbang Wetan dilaksanakan di Balai Pemuda yang bertempat di tengah kota Surabaya. Hal yang mendasari pemilihan tempat ini dikarenakan akses menuju lokasi mudah untuk dijangkau semua kalangan dan tempatnya terbuka.

Enam tahun setelah Kenduri Cinta berdiri, lahir komunitas pengajian serupa di Surabaya bernama Bangbang Wetan pada September 2006. Berawal dari pertemuan di MPM Honda yang dihadiri kurang lebih 25 orang termasuk Cak Nun sendiri. Orang yang hadir pada pertemuan tersebut yakni terdiri dari beberapa jamaah Padhangmbulan yang berdomisili di Surabaya dan Sidoarjo. Hal ini terlaksana atas arahan dari tim Progress Yogyakarta yang meminta beberapa jamaah tersebut untuk menjadi pelaksana dalam pertemuan dengan melibatkan pihak-pihak luar.

Bertempat di MPM Honda, pertemuan awal ini melibatkan beberapa unsur, termasuk perwakilan MPM Honda, Dewan Kesenian Surabaya, dan tokoh lintas agama. Dari pertemuan tersebut menghasilkan kesepakatan tetang bentukan forum dan nama komunitas.

Lalu, dalam pertemuan itu Cak Nun menjelaskan arti Bangbang Wetan yang merupakan istilah abang-abang teko wetan atau sinar yang memancar dari timur sebagai tanda munculnya pencerahan, dalam Islam juga dikenal dengan idiom mindah-dhulumat ila an-nuur. Sebenarnya nama Bangbang Wetan ini diusulkan, oleh Cak Priyo yang diterima Cak Nun.

Pada pengajian pertama, atau tepatnya satu hari setelah pengajian Padhangmbulan diselenggarakan pada September 2006, Bangbang Wetan pun diselenggarakan di Balai Pemuda Surabaya. Pada tahap-tahap awal ini, Cak Nun menjelaskan bahwa pengajian ini dikonsep egaliter berbeda dengan pengajian konvensional pada umumnya.

\section{Sejarah Berdirinya Pengajian Maiyah Jamparing Asih}

Awal mula berdirinya pengajian Jamparing Asih sudah mulai terlihat di tahun 2000-an. Sebuah forum bernama Tali Kaasih mulai dibentuk sebagai Event Organizer yang menangani kegiatan pengajian Cak Nun di Bandung tepatnya di masjid Pusdai. Namun, forum tersebut tidak bertahan lama hanya sekitar satu tahun dan terhenti dikarenakan satu dan lain hal. ${ }^{27}$

${ }^{27}$ Andityas Praba, Wawancara dengan salah satu Jamaah Jamparing Asih pada 13 Maret 2020 pukul 19.03 WIB. 
Pola Pengajian Kultural Ma'iyah Jamparing Asih di Bandung 2015-2018| Akbar Nur Alamsyah, dkk

Kemudian pada Agustus 2015 merupakan titik balik bagi beberapa orang dari Tali Kaasih untuk berkumpul kembali pada saat Cak Nun menghadiri acara pengajian yang diselenggarakan Penerbit Mizan di Cinambo. Setelah dilaksanakannya acara pengajian tersebut, orang-orang yang tersisa dari Tali Kaasih yakni; Wawan, Mufti, Andityas dan Nissa berkumpul, membahas keinginan mereka untuk mengadakan kembali pengajian Cak Nun di Bandung dengan nama Jamparing Asih. Guna menindak lanjuti hasil kumpulan tersebut, beberapa penggiat diantaranya; Wawan, Mufti dan Andityas diminta hadir ke Jakarta dikediaman Syeikh Kamba pada November 2015 untuk merumuskan bentukan forum pengajian. $^{28}$

Dalam pertemuan tersebut dihadiri beberapa penggiat dari Kenduri Cinta, Syeikh Kamba dan Cak Nun sendiri. Pada pertemuan itu, Cak Nun menanayakan nama yang akan digunakan apakah akan menggunakan nama yang sudah disepakati sebelumnya atau akan membuat nama baru. Salah satu penggiat yakni Wawan meyakinkan Cak Nun untuk menggunakan nama yang ada dan telah disepakati sebelumnya yakni Jamparing Asih. Nama tersebut memiliki arti Panah Cinta, merupakan secercah doa dan harapan agar forum dapat menebarkan atau menghunjamkan cinta bagi siapa saja yang berada dalam lingkarannya. Nama tersebut pun disetujui oleh Cak Nun. ${ }^{29}$

Jamparing Asih pertama kali menyelenggarakan pengajian Maiyah (selanjutnya disebut maiyahan) pada 19 Desember 2015 di ruang studio Radio Republik Indonesia (RRI) Bandung. Jamaah yang hadir pada waktu itu diperkirakan berjumlah 50 orang terdiri dari berbagai latar belakang seperti; Mahasiswa, Buruh, Dosen, Guru, Budayawan, dan lain-lain. ${ }^{30}$

Pada perkembangannya maiyahan terus berlangsung sebulan sekali di ruang studio RRI Bandung hingga September 2016, karena beberapa hal yang berkaitan dengan finansial dan bergantinya masa kepengurusan RRI Bandung, maiyahan tidak bisa lagi dilaksanakan di studio RRI Bandung. Kondisi itu membuat para penggiat dan jamaah berpikir untuk mencari tempat lain, maiyahan juga pernah dilaksanakan di halaman SMK Al-Hadi dan Gedung PWNU Jawa Barat sebelum akhirnya pada bulan April 2017

${ }^{28}$ Andityas Praba, Wawancara dengan salah satu Jamaah Jamparing Asih pada 13 Maret 2020 pukul 19.03 WIB.

${ }^{29}$ Redaksi Jamparing Asih, Medar Kedaulatan. (Bandung: TP 2015), 2.

${ }^{30}$ Andityas Praba 
Pola Pengajian Kultural Ma'iyah Jamparing Asih di Bandung 2015-2018| Akbar Nur Alamsyah, dkk

hingga Desember 2018 maiyahan diselenggarakan di Aula Pondok Pesantren Anak Jalanan At-tamur.

\section{Pola Pengajian Maiyah Jamparing Asih 2015-2018}

Pengajian nonformal sering disamakan oleh masyarakat sebagai majelis taklim. Secara bahasa majelis taklim berasal dari bahasa arab yang terdiri dari dua suku kata; majelis yang berarti tempat duduk dan taklim yang berarti belajar. Dengan demikian yang dimaksud dengan majelis taklim adalah tempat belajar. Adapun secara istilah majelis taklim sendiri merupakan lembaga pendidikan nonformal yang memiliki jamaah dengan jumlah yang relatif banyak, usia yang heterogen, memiliki waktu yang fleksibel sesuai kebutuhan jamaah, di dalamnya membahas keilmuan agama Islam atau yang lainnya. ${ }^{31}$

Kegiatan pengajian nonformal seperti ini karena lebih fleksibel dapat dikategorikan polanya:

Dilihat dari segi waktu:

1. Pengajian mingguan yang dilaksanakan seminggu sekali. Untuk harinya menyesuaikan dengan kondisi dan waktu yang ada. ${ }^{32}$

2. Pengajian bulanan yang dilaksanakan setiap satu bulan sekali, bisa minggu pertama, minggu kedua dan seterusnya. ${ }^{33}$

3. Pengajian tahunan yang dilaksanakan satu tahun sekali, biasanya pengajian seperti ini dilaksanakan untuk memperingati hari besar Islam atau haul (peringatan wafat seseorang). ${ }^{34}$

Dilihat dari segi materi pengajian:

1. Tafsir alquran. Kajian tentang tafsir alquran sangat menunjang pelajaran- pelajaran yang lain, sebab ayat-ayat alquran berisi tentang ajaran tauhid, hukum, akhlak, sejarah, fiqh dan pengetahuan umum. Sebagai seorang muslim harus berusaha mengetahui isi dari alquran yang menjadi kitab sucinya. ${ }^{35}$

2. Tauhid merupakan pondasi Islam, karena pembahasannya mengenai eksistensi Allah dan hal yang berhubungan dengan-Nya. Tauhid berisi

${ }^{31}$ Muhsin, MK, Manajemen Majelis Taklim: Petunjuk Praktis Pengelolaan dan Pembentukannya. (Jakarta: Pustaka Intermasa 2009), 1.

${ }^{32}$ Muhsin, MK. 10.

${ }^{33}$ Muhsin, MK,. 10 .

${ }^{34}$ Muhsin, MK, 10.

${ }^{35}$ Mahmud Yunus, Sejarah Pendidikan Islam di Indonesia. 17. 
Pola Pengajian Kultural Ma'iyah Jamparing Asih di Bandung 2015-2018| Akbar Nur Alamsyah, dkk

pengajaran keimanan yang meliputi rukun iman. Ajaran tauhid ini dapat diperluas lagi dengan manifestasi rukun iman, yakni dengan cara mengamalkannya dalam kehidupan sehai-hari, tidak sekedar mengetahui atau menghafalkannya saja. ${ }^{36}$

3. Hadits merupakan perkataan, perbuatan Rasulullah atau yang lebih dikenal dengan sabda Rasulullah. Hadits atau sunnah berisikan halhal yang berkaitan dengan tauhid, hukum, akhlak dan sebagainya. Dalam pengajian penyampaiannya harus disesuaikan dengan masalah yang sedang dibahas. ${ }^{37}$

4.Akhlak. Kajian ini bisa dibagi menjadi tiga bagian yakni; akhlak manusia kepada Allah SWT, akhlak manusia kepada sesamanya dan akhlak manusia kepada sesama makhluk ciptaan-Nya. ${ }^{38}$

5. Fiqih. kajian fiqih mencakup dua bidang, yaitu fiqih ibadah yang mengatur hubungan manusia dan Allah seperti shalat, puasa, zakat dan haji. Kemudian fiqih muamalah yakni mengatur tentang hubungan manusia dengan sesamanya. Pembahasannya mencakup jual-beli, perkawinan, perceraian, ketentuan pembagian harta dan lain-lain. ${ }^{39}$

6. Tarikh. Kajian ini adalah kajian tentang sejarah Rasulullah dalam menggambarkan betapa besarnya pengorbanan yang dilakukan Rasulullah dan umat-umat terdahulu dalam memperjuangkan Islam. ${ }^{40}$

7. Selain materi-materi yang sudah disebutkan di atas, biasanya dalam pengajian juga diberikan materi-materi umum. materi umum adalah pengajian yang materinya bersifat umum yang berkaitan dengan kehidupan, biasanya diisi ceramah oleh seorang ustaz atau guru dan adakalanya diadakan dialog tanya jawab ataupun diskusi (mudzakarah). Selain itu, pengajian umum juga bermakna pengajian yang dihadiri oleh masyarakat umum dari berbagai lapisan masyarakat. $^{41}$

Dilihat dari segi penyelenggara:

${ }^{36}$ Mahmud Yunus. 17.

${ }^{37}$ Mahmud Yunus. 17.

${ }^{38}$ Mahmud Yunus. 17.

${ }^{39}$ Mahmud Yunus. 17.

${ }^{40}$ Mahmud Yunus. 17.

${ }^{41}$ Muhsin, MK, Manajemen Majelis Taklim: Petunjuk Praktis Pengelolaan dan Pembentukannya, 11. 
Pola Pengajian Kultural Ma'iyah Jamparing Asih di Bandung 2015-2018| Akbar Nur Alamsyah, dkk

1. Instansi pemerintahan. Pengajian yang diadakan oleh instansi pemerintahan biasanya diadakan pada saat hari besar atau suatu peristiwa penting dalam suatu negara. ${ }^{42}$

2. Organisasi. Pengajian yang diadakan oleh organisasi seperti Nahdatul Ulama, Muhammadiyah, Persatuan Islam, Lembaga Dakwah Islam Indonesia dan lain-lain. ${ }^{43}$

3. Komunitas. Pengajian yang diadakan oleh komunitas biasanya diadakan dengan waktu tertentu sesuai kesepakatan anggota komunitas. $^{44}$

Dari penjelasan di atas maka pengajian Jamparing Asih di Bandung tahun 2015-2018 bisa dilihat pola pengajiannya berdasarkan segi waktu, segi jamaah, segi materi, dan segi penyelenggara.

\section{Metode Pengajian Maiyah Jamparing Asih 2015-2018}

Adapun faktor-faktor yang membuat keberhasilan dalam pengajian nonformal atau majelis taklim adalah metode yang digunakan dalam menyampaikan tema atau materi. Berikut merupakan metode yang digunakan pengajian nonformal atau majelis taklim:

\section{Metode Ceramah}

Di dalam majelis taklim metode ceramah ini pada pelaksanaannya memiliki dua cara; pertama, narasumber atau guru bertindak aktif dengan memberikan pelajaran, sedangkan jamaahnya berperan pasif hanya mendengarkan atau menerima materi yang disampaikan. Kedua, ceramah terbatas, di mana biasanya terdapat kesempatan untuk bertanya jawab. Jadi narasumber atau guru dengan jamaah sama-sama aktif. ${ }^{45}$

2. Metode halaqah

Dalam metode ini narasumber atau guru memberikan pelajaran dengan memegang satu kitab atau buku tertentu. Jamaah yang mendengarkan keterangan guru sambil menyimak kitab atau buku yang sama atau melihat ke papan tulis di mana guru menuliskan hal-hal yang disampaikannya. Metode ini berbeda dengan metode ceramah di mana peranan guru sebagai pembimbing jauh lebih aktif karena guru seringkali harus mengulang-ulang

${ }^{42}$ Muhsin, MK. 12.

${ }^{43}$ Muhsin, MK. 12.

${ }^{44}$ Muhsin, MK. 12.

${ }^{45}$ Helmawati, Pendidikan Nasional dan Optimalisasi Majelis Ta'lim: Peran Aktif Majelis Ta'lim Meningkatkan Mutu Pendidikan. (Jakarta: Rineka Cipta 2013), 93. 
Pola Pengajian Kultural Ma'iyah Jamparing Asih di Bandung 2015-2018| Akbar Nur Alamsyah, dkk

sesuatu bacaan yang ditirukan oleh jamaah serta membetulkan bacaan yang salah. $^{46}$

\section{Metode Mudzakarah}

Metode ini dilaksanakan dengan cara tukar pendapat atau diskusi mengenai suatu masalah yang telah disepakati untuk dibahas. Metode ini sering digunakan jamaah jika narasumber atau guru sedang berhalangan hadir. ${ }^{47}$

4. Metode campuran

Metode ini berarti satu majelis taklim menyelenggarakan kegiatan pengajian tidak dengan satu macam metode saja, melainkan mengkombinasikan berbagai metode secara berselang-seling. ${ }^{48}$

Dari penjelasan di atas mengenai metode pengajian, maka bisa kita lihat metode apa yang digunakan oleh pengajian Jamparing Asih pada setiap pengajian diselenggarakan mulai dari Desember 2015 hingga Desember 2018.

\section{Simpulan}

1. Pengajian Maiyah diawali oleh pengajian Padhangmbulan di Jombang pada Oktober 1993. Pengajian tersebut didirikan oleh Cak Nun dan keluarganya. Dari pengajian tersebut kemudian tersebar dan berdiri pengajian Maiyah lainnya di berbagai daerah seperti; didirikannya pengajian Mocopat Syafaat di Yogyakarta pada Juni 1999, kemudian pengajian Gambang Syafaat di Semarang pada Desember 1999, kemudian pengajian Kenduri Cinta di Jakarta pada Juni 2000 dan pengajian Bangbang Wetan di Surabaya pada September 2006.

2. Proses atau tahapan berdirinya pengajian Jamparing Asih berawal dari acarangaji bareng Cak Nun yang diselenggarakan oleh penerbit Mizan di Cinambo pada 21 Agustus 2015. Setelah acara itu diselenggarakan, Wawan, Mufti, Andityas dan Nissa berkumpul dan membahas keinginannya untuk mendirikan pengajian Maiyah di Bandung yang dinamai Jamparing Asih. Selanjutnya setelah perkumpulan itu diadakan, Wawan, Mufti dan Andityas pada bulan November 2015 diundang ke kediaman Syeikh Kamba di Jakarta

${ }^{46}$ Helmawati, Pendidikan Nasional dan Optimalisasi Majelis Ta'lim: Peran Aktif Majelis Ta'lim Meningkatkan Mutu Pendidikan. (Jakarta: Rineka Cipta 2013), 93.

${ }^{47}$ Helmawati, Pendidikan Nasional dan Optimalisasi Majelis Ta'lim: Peran Aktif Majelis Ta'lim Meningkatkan Mutu Pendidikan. (Jakarta: Rineka Cipta 2013), 94.

${ }^{48}$ Helmawati, Pendidikan Nasional dan Optimalisasi Majelis Ta'lim: Peran Aktif Majelis Ta'lim Meningkatkan Mutu Pendidikan. (Jakarta: Rineka Cipta 2013), 94. 
Pola Pengajian Kultural Ma'iyah Jamparing Asih di Bandung 2015-2018| Akbar Nur Alamsyah, dkk

untuk bertemu Cak Nun guna membahas lebih lanjut mengenai pengajian yang akan didirikan di Bandung.

Dalam pertemuan tersebut dihadiri beberapa penggiat dari Kenduri Cinta, Syeikh Kamba dan Cak Nun sendiri. Pada pertemuan itu, Cak Nun menanayakan nama yang akan digunakan apakah akan menggunakan nama yang sudah disepakati sebelumnya atau akan membuat nama baru. Salah satu penggiat yakni Wawan meyakinkan Cak Nun untuk menggunakan nama yang ada dan telah disepakati sebelumnya yakni Jamparing Asih. Maka hasil dari pertemuan tersebut Jamparing Asih resmi didirikan pada November 2015.

3. Pola pengajian Jamparing Asih sepanjang tahun 2015 sampai 2016 jika dilihat hampir seluruhnya bisa dikategorikan ke dalampengajian umum. Namun terdapat sedikit perubahan pada bulan April dan Mei 2016 pada saat itutema atau materi bisa dikategorikan ke dalam pengajian tafsir alquran dan di bulan Juni pola pengajian jika dikategorikan masuk ke dalam pengajian fiqh. Selain bulan Apri, Mei dan Juni, pola pengajian Jamparing Asih didominasi oleh tema atau materi pengajian umum.

Kemudian di tahun 2017 pola pengajian Jamparing Asih hampir seluruhnya bisa dikategorikan ke dalam pengajian tafsir alquran. Dalam tahun 2017 perubahan pola pengajian terlihat di bulan Mei dan Desember jika dikategorikan masuk ke dalam pengajian umum. Selain bulan Mei dan Desember, pola pengajian Jamparing Asih dominan pengajian tafsir alquran.

Selanjutnya di tahun 2018 pola pengajian Jamparing Asih hampir seluruhnya jika dikategorikan masuk ke dalam pengajian umum. Ada perubahan pola pengajian pada bulan April dan Mei yang menjadi pengajian tafsir alquran dan pada bulan September menjadi pengajian akhlak. Kendati demikian selain bulan April, Mei dan September, pengajian Jamparing Asih didominasi menggunakan pola pengajian umum.

Dari uraian di atas bisa kita lihat perkembangan dan perubahan pola pengajian yang digunakan Jamparing Asih di tahun 2015 dan 2016 hampir seluruhnya menggunakan pola pengajian umum. Kemudian di tahun 2017 hampir seluruhnya menggunakan pola pengajian tafsir alquran dan di tahun 2018 hampir seluruhnya menggunakan pola pengajian umum.

Metode pengajian Jamparing Asih sepanjang tahun 2015 dan 2016 lebih banyak menggunakan metode ceramah dalam pelaksanaan pengajian. 
Pola Pengajian Kultural Ma'iyah Jamparing Asih di Bandung 2015-2018| Akbar Nur Alamsyah, dkk

Namun, perubahan metode terjadi di bulan Februari, Mei, Juni, September dan Oktober 2016 yakni menggunakan metode mudzakarah atau diskusi. Penggunaan metode mudzakarah dikarenakan di bulan-bulan tersebut pengajian tidak dihadiri oleh guru atau narasumber, jika guru atau narasumber hadir maka metode yang digunakan pada pengajian adalah metode ceramah.

Kemudian di tahun 2017 pengajian Jamparing Asih hampir seluruhnya menggunakan metode mudzakarah, hanya di bulan November metode yang digunakan adalah metode ceramah. Selanjutnya di tahun 2018 pengajian Jamparing Asih jika dilihat hampir seluruhnya menggunakan metode mudzakarah hanya sedikit perubahan di bulan Februari, Oktober dan November yang menggunakan metode ceramah.

Dari uraian di atas bisa kita lihat perkembangan dan perubahan metode pengajian yang digunakan Jamparing Asih di tahun 2015 dan 2016 hampir seluruhnya menggunakan metode ceramah. Kemudian di tahun 2017 hampir seluruhnya menggunakan metode mudzakarah atau diskusi dan di tahun 2018 hampir seluruhnya menggunakan mudzakarah atau diskusi.

\section{E. Daftar Sumber \\ Buku}

A. Hasjmy, (1993), Sejarah Masuk dan Berkembangnya Islam di Indonesia, Al- Ma'arif.

Emha Ainun Nadjib, (2016), Saat-saat Terakhir Bersama Soeharto 2,5 Jam di Istana. Yogyakarta: Bentang Pustaka.

Helmawati, (2013), Pendidikan Nasional dan Optimalisasi Majelis Ta'lim: Peran Aktif Majelis Ta'lim Meningkatkan Mutu Pendidikan. Jakarta: Rineka Cipta.

Kuntowijoyo, (2001), Pengantar Ilmu Sejarah, Yogyakarta: Bentang Budaya.

Kuntowijoyo, (2006), Budaya dan Masyarakat. Yogyakarta: Tiara Wacana. Louis Gottscalk, (1986), Mengerti Sejarah. Jakarta: UI Press.

Mahmud Yunus, (1996), Sejarah Pendidikan Islam di Indonesia. Jakarta: Hadikarya Agung.

Muhammad Nursamad Kamba, (2018), Kids Zaman Now Menemukan Kembali Islam. Tangerang Selatan: Pustaka IIman.

Muhsin, MK, (2009), Manajemen Majelis Taklim: Petunjuk Praktis Pengelolaan dan Pembentukannya. Jakarta: Pustaka Intermasa. 
Pola Pengajian Kultural Ma'iyah Jamparing Asih di Bandung 2015-2018| Akbar Nur Alamsyah, dkk

Martin van Bruinessen, (2015), Kitab Kuning, Pesantren dan Tarekat, Yogyakarta: Gading Publishing.

Noeng Muhadjir, (1987), Ilmu Pendidikan dan Perubahan Sosial Suatu Teori Pendidikan, Yogyakarta: Rake Sarasin.

Paul Veyne, (1984), Writing History: Esay on Epistimology. Conneticut: Wesleyan University Press.

Prayogi R. Saputra, (2012), Spiritual Jourey; Pemikiran \& Permenungan Emha Ainun Nadjib. Jakarta: Kompas.

Zamakhsyari Dhofier, (2011), Tradisi Pesantren: Studi Pandangan Hidup Kyai dan Visinya Mengenai Masa Depan Indonesia. Jakarta: LP3S.

\section{Jurnal dan Artikel}

Aisyah Nursyarief, (2014), Pendidikan Islam di Indonesia Dalam Lintasan Sejarah, Jurnal Lentera Pendidikan, Vol. 17 No. 2, Makassar: UIN Alaudidin Makassar.

Anonim "Sunda Mengasuh" Redaksi Jamparing Asih (2015)

Artikel Mukadimah Jamparing Asih sepanjang tahun 205-2018.

Anif Khoiriyah, (2019), Skripsi Implementasi Metode Dakwah Untuk Mengembangkan Kecerdasan Spiritual Jamaah Pada Maiyah Gambang Syafaat. Universitas Islam Negeri Walisongo: Semarang.

Cak Rud, (2015), Bangbang Wetan Kate Lapo. Bulletin Maiyah Jawa Timur, Edisi Khusus September.

Caknun.com, (2020), Meletakkan Solusi Bulatan ke dalam Solusi Segitiga Cinta. https://caknun.com/2016/meletakkan-solusi-bulatan-ke-dalam-solusisegitiga- cinta/

Fahmi Agustian, (2016) Maiyah Sebagai Kata Kerja. https://www.caknun.com/2016/Maiyah-sebagai-kata-kerja/

Fahmi Agustian, (2019), Pengajian Kok Begitu: 10 Hal untuk Millenial Ketahui Tentang Sinau Bareng Cak Nun dan Kiai Kanjeng. Progress: Yogyakarta.

Fahmi Agustian, (2020), Liqo'un 'Adhim di Pesantren Anak Jalanan Attamur. https://caknun.com/2018/liqoun-adhim-di-pesantren-anak-jalanan-at$\underline{\text { tamur }}$

Imam Mubarrok, Implikasi Konsep Cinta Maiyah Emha Ainun Nadjib Terhadap Jamaahnya. Universitas Islam Negeri Bandung: Bandung.

Komunitas Maiyah Kenduri Cinta, (2016), Padhangmbulan Sebagai Ibu Maiyah. Jakarta: Redaksi Kenduri Cinta.

Moh. Syafi'il Anam, (2019), Jurnal Dirasah, Vol.2 No.1 Sistem Pembelajaran Majelis Taklim Padhang Mbulan Dalam Mewujudkan Learning Society (Studi Majelis Ilmu Maiyah Padhang Mbulan Jombang Jawa Timur). Insititut Agama Islam Diponegoro Nganjuk: Nganjuk. 
Pola Pengajian Kultural Ma'iyah Jamparing Asih di Bandung 2015-2018| Akbar Nur Alamsyah, dkk

Nafisatul Wakhdiah, Fahmi Agustian, (2015), Silaturrahmi Nasional II Penggiat Maiyah 2015. https://caknun.com/2015/silaturahmi-nasionalii-penggiat- maiyah-2015/

Redaksi Kenduri Cinta (2016), Padhangmbulan Sebagai Ibu Maiyah. Redaksi Jamparing Asih, (2015), Medar Kedaulatan.

Rini Wulan, (2018), Skripsi Retorika Emha Ainun Nadjib dalam Kajian Kenduri Cinta di Taman Ismail Marzuki Jakarta Pusat. Bandung: Universitas Islam Negeri Sunan Gunung Djati Bandung.

Rony K. Pratama, (2019), Rubrik Maiyahan. Mencari Akar Meneladani Sesepuh Padhangmbulan. $\quad$ https://www.caknun.com/2019/mencariakar-meneladani- $\quad$ sesepuh-padhangmbulan/

Witarko dan Junanah, (2017) Ringkasan Tesis Pendidikan Nilai-Nilai Multikultural Dalam Forum Maiyah Mocopat Syafaat di Tamantirto Kasihan Bantul. $\quad$ Yogyakarta:TP.

\section{Wawancara}

Andityas Praba, (2020), Wawancara dengan salah satu Jamaah Jamparing Asih pada 13 Maret pukul 19.03 WIB.

Muhammad Nadhir Mu'ammar, (2020), Wawancara dengan salah satu Jamaah Jamparing Asih pada 4 Maret 2020 pukul 16.00 WIB.

Muhammad Nursamad Kamba, (2020), Wawancara dengan salah satu marja' atau guru di pengajian Maiyah pada 12 Maret pukul 15.51 WIB. 